\title{
Is there a logic of information?
}

\begin{abstract}
Information-based epistemology maintains that 'being informed' is an independent cognitive state that cannot be reduced to knowledge or to belief, and the modal logic KTB has been proposed as a model. But what distinguishes the KTB analysis of 'being informed', the Brouwersche schema $(B)$, is precisely its downfall, for no logic of information should include $(B)$. Yet, without (B), there is little hope for an independent model logic of 'being informed' and subsequently little reason to presume that 'being informed' is a novel cognitive state.
\end{abstract}

Keywords: Modal logic, logic of 'being informed'.

A the heart of Luciano Floridi's information-based epistemology is the claim that 'being informed' is an independent cognitive state that cannot be reduced to knowledge or to belief (Floridi 2011). According to Floridi (2006), the box operator of the normal modal logic KTB captures the salient features of a subject S's state of being informed that $p$. Unlike mere belief, being informed is factive: $\mathrm{S}$ is informed that $p$ only if $p$ is true; in other words,

(T) $\quad \square p \rightarrow p$.

Unlike true belief, being informed is also constructive: $\mathrm{S}$ is informed that $p$ only if $\mathrm{S}$ is informed that he is not informed that not- $p$. However, $\mathrm{S}$ may well be informed that $p$ without being informed that he is informed that $p$, which means that being informed is conceived to be neither transitive nor Euclidean, and therefore is too weak for the modal system S5. The independence thesis follows accordingly.

But what distinguishes the KTB analysis of being informed, the Brouwersche schema,

(B) $\quad p \rightarrow \square \diamond p$, is precisely its failing, for no logic of information should include $(B)$. 
To see why, observe that the modal system KTB is closed under the inference rule $\mathrm{RR},{ }^{1}$ by virtue of being a regular system (Chellas 1980: 235), and has as theorems a pair of schemas that, for reasons which will soon become clear, I shall call the 'Bombs Away LeMay' schemas, or BAM for short.

$$
\begin{aligned}
& (\text { BAM 1) } \square(p \rightarrow \square q) \rightarrow(\diamond p \rightarrow q) . \\
& (\text { BAM 2) } \square(\diamond p \rightarrow q) \rightarrow(p \rightarrow \square q) .
\end{aligned}
$$

BAM licenses exchanges of information that no logic of information should abide by. Consider a pair of examples exercising each schema.

Case 1. Suppose Kennedy is informed of the following condition: if Cuba launches its missiles $(p)$, then Kennedy is informed that the US is at war $(\square q)$. Courtesy of BAM 1, it follows that if Kennedy is not informed that Cuba does not launch its missiles $(\diamond p)$, then the US is at war.

Case 2. In Babylonia, everyone believes that the circumference of a circle is thrice its diameter plus one-eighth. Now suppose that Hammurabi is informed of the following dilemma: either he is informed that $\pi$ is a rational number $(\square p$ ) or Hesperus is Phosphorus ( $q$ ). Through BAM 2, it follows that Hammurabi has the information that Hesperus is Phosphorus $(\square q)$ if $\pi$ is not a rational number $(\sim p){ }^{2}$ So, Hammurabi has the information that Hesperus is Phosphorus.

One might wonder how to avoid BAM, but a look at the proof below reveals that the $(B)$ schema is a deep source of trouble. For not only is BAM set off in every normal system that includes $(B)$, BAM is set off in every regular (non-normal) system that includes $(B) .^{3}$ BAM pops up in $S 5$, too, but the introspection conditions afforded by the (4) schema work to ameliorate the harm. ${ }^{4}$ Put differently, when

\footnotetext{
${ }^{1}$ Rule RR states that if $(p \& \mathrm{q}) \rightarrow r$ is a theorem, then $\square(p \& \mathrm{q}) \rightarrow \square r$ is too.

2 Specifically, BAM2 here is $\square(\diamond \sim p \rightarrow q) \rightarrow(\sim p \rightarrow \square q)$ and $p$ codes ' $\pi$ is a rational number'. ${ }^{3}$ Compare to Allo (2011), who proposes a non-normal weakening of the $K T B$ analysis that nevertheless succumbs to BAM.

${ }^{4}$ Schema (4) is $\square p \rightarrow \square \square p$.
} 
surveying the options available for a modal logic of information by weakening $S 5$, the path that includes (B) is paved with BAM straight down to the regular systems. BAM therefore presents a fundamental problem for the logic of information, one that is sharper than information closure (Floridi 2011, Dretske 2006), for the BAM schemas illustrate precisely why being informed does not, and should not, adhere to the strictures of constructive proof.

Without $(B)$, there is no BAM. Yet without $(B)$ there is little hope for an independent modal logic of 'being informed' and therefore little reason to think that being informed is a novel cognitive state that demands its own logic and is in need of its own philosophy. ${ }^{5}$

Proof of $(B A M)$ :

$B A M 1$

1) $(\square \sim \square q \& \diamond p) \rightarrow$ $\diamond(\sim \square q \& p)$

2) $\square(p \rightarrow \square q) \rightarrow(\diamond p \rightarrow \diamond \square q)$

3) $\diamond \square q \rightarrow q$

4) $\square(p \rightarrow \square q) \rightarrow(\diamond p \rightarrow q)$
$B A M 2$
1) $\square(\diamond p \rightarrow q) \rightarrow$
$(\square \diamond p \rightarrow \square q)$
2) $\square(\diamond p \rightarrow q) \rightarrow$
$(\sim \square q \rightarrow \diamond \square \sim p)$
Rewrite 1
3) $\diamond \square \sim p \rightarrow \sim p$
$(B \diamond)$
4) $\square(\diamond p \rightarrow q) \rightarrow(\sim \square q \rightarrow \sim p)$
$2,3 P L$
5) $\square(\diamond p \rightarrow q) \rightarrow(p \rightarrow \square q) \quad$ Rewrite 4

$(B \diamond)$

2, $3 P L$

\section{References:}

Allo, P. 2011. The logic of 'being informed' revisited and revised. Philosophical Studies 153: 427-34.

Chellas, B. 1980. Modal Logic. Cambridge University Press, Cambridge.

Dretske, F. 2006. Information and closure. Erkenntnis 64: 409-13.

Floridi, L. 2006. The logic of 'being informed'. Logique and Analyse 49:433-60.

Floridi, L. 2011. The Philosophy of Information. Oxford University Press, Oxford.

\footnotetext{
5 Thanks to ...
} 